\title{
Infections in Hospitalized Cancer Patients
}

\author{
Amanda Delgado ${ }^{\mathrm{a}}$, Achuta Kumar Guddati ${ }^{\mathrm{a}} \mathrm{b}$
}

\begin{abstract}
Cancer patients are at an increased risk of developing infections that are primarily treatment-driven but may also be malignancy-driven. While cancer treatments such as chemotherapy, radiotherapy, and surgery have been known to improve malignancy morbidity and mortality, they also have the potential to weaken immune defenses and induce periods of severe cytopenia. These adverse effects pave the way for opportunistic infections to complicate a hospitalized cancer patient's clinical course. Understanding the risk each patient inherently has for developing a bacterial, fungal, or viral infection is critical to choosing the correct prophylactic treatment in conjunction with their scheduled cancer therapy. This review discusses the most common types of infections found in hospitalized cancer patients as well as the current guidelines for prophylactic and antimicrobial treatment in cancer patients. In addition, it describes the interaction between antibiotics and cancer therapies for consideration when treating infection in a cancer patient.
\end{abstract}

Keywords: Cancer; Infection; Morbidity; Mortality

\section{Introduction}

The relationship between infections and cancer is complex. Some infections increase a persons' chance of developing cancer. Conversely, immunocompromised cancer patients are more susceptible to contracting certain infections. The infections most commonly seen in cancer patients are changing with evolving treatment modalities. Understanding the connection between cancer and infection is necessary when evaluating current treatment recommendations established by various societies. It is known that a number of viral and bacterial infections are associated with an increased risk of developing specific types of cancer. For example, hepatitis B and C, human papillomaviruses, and Helicobacter pylori are responsible

Manuscript submitted August 17, 2021, accepted October 1, 2021

Published online December 8, 2021

aDivision of Hematology/Oncology, Georgia Cancer Center, Augusta University, Augusta, GA 30912, USA

bCorresponding Author: Achuta Kumar Guddati, Division of Hematology/ Oncology, Georgia Cancer Center, Augusta University, Augusta, GA 30912, USA. Email: aguddati@augusta.edu

doi: https://doi.org/10.14740/wjon1410 for liver, cervical, and gastric cancers, respectively. In 2008, nearly $16 \%$ of new cancer cases were preceded by infections [1]. Public health measures including vaccines and antibiotics should have a substantial impact on the global cancer burden attributed to infections. It is also known that cancer patients are at an increased risk of developing infections for a number of reasons. Risk factors for developing an infection are primarily categorized as malignancy driven or treatment driven.

Solid tumor malignancies increase the risk of developing an infection via fistula formation or obstruction of a biologic passageway [2]. Under normal conditions, mucosal surfaces function as anatomical barriers, keeping invasive pathogens at bay. However, solid tumors have the capacity to introduce pathologic by way of broncho-pleural, trachea-esophageal, vesico-vaginal or recto-vaginal fistulas [2]. Tumors also have the ability to obstruct essential body passages. For example, expanding tumors that impede airway function may facilitate post-obstructive pneumonia [3]. Post-obstructive pneumonia may either overlap with bacterial community-acquired pneumonia or present as a unique entity, limiting the ability to make a clinical distinction at the time of admission [3]. Solid tumor obstructions of the biliary tract, urethra, and bowel also increase the risk of infection in cancer patients [2]. While surgical resection of solid tumors improves cancer patient mortality, it also introduces the additional risk of developing an infection. Medical procedures combined with the increasing use of inpatient medical devices directly increase a patient's risk of acquiring a nosocomial infection [4]. Conventional chemotherapy and radiation therapy are also infectious risk factors in cancer patients. These treatments damage mucosal surfaces and increase the likelihood of microbial colonization and subsequent mucositis [2].

Toxic antineoplastic chemotherapies and myelosuppressive agents used to treat hematologic cancers compromise the immune system by suppressing the absolute neutrophil count below 500 cells $/ \mathrm{mm}^{3}$ during episodes of neutropenia [2]. Neutropenia increases morbidity, mortality, and treatment costs for cancer patients by placing them at a higher risk of developing life-threatening infections with few symptoms $[5,6]$. Bacterial infections commonly present in the early stages of neutropenia while fungal infections present during persistent neutropenic episodes lasting 7 - 10 days [7]. Research on cancer treatment has shifted from nonspecific chemotherapies to targeted treatments and immunotherapies. Targeted therapies are designed to slow tumor growth or progression by interfering with specific molecular targets [8]. Similarly, immunotherapies are selective therapeutics that target specific immune checkpoint inhibitors to overcome immune tolerance to tumors and produce anti-cancer responses $[9,10]$. While cytotoxic chemotherapies 
have an infectious risk directly proportional to the degree and duration of myelosuppression, it is less apparent what the infectious risk is with targeted therapies and immunotherapies [11]. Although rare, immune-related adverse events, including neutropenia, are severe side effects of immunotherapies [12]. As more patients become eligible for immune checkpoint inhibition therapy, the incidence of severe toxicities may rise. Other factors that impact a cancer patient's susceptibility to developing an infection include age, nutritional status, and prior antibiotic exposure [2]. It is of utmost importance to understand the risk factors each cancer patient has for developing an infection in order to guide prophylactic antimicrobial treatment. This paper will discuss the most common infections seen in cancer patients today and the interactions between antibiotics and cancer therapy. Additionally, it will outline recommendations for treating infections in cancer patients put forth by various societies.

\section{Common Types of Infections in Cancer Pa- tients}

Infections in cancer patients differ by anatomical location, source, and duration of cancer treatment. Patients with solid tumors commonly harbor infections caused by organisms that mirror the individual's resident microflora at the specific site of infection $[2,13]$. The incidence of some infections in cancer patients closely mirrors that of seasonal incidence in the general population. Other organisms are opportunistic, infecting patients with weakened immune defenses as a result of cytotoxic chemotherapies. Various societies have provided guidelines for treating infections in cancer patients, and special consideration should be given to the interaction between antibiotics and cancer therapies. The frequency and treatment of most common pathogens on cancer patients were summarized in Table 1 [14-20].

\section{Gram-positive bacteria}

Gram-positive bacteria are responsible for at least $50 \%$ of infections acquired by cancer patients [21]. Nearly $80 \%$ of catheter-related infections are caused by gram-positive organisms [2]. Staphylococci, streptococci, and enterococci carry the greatest burden of disease [22]. Staphylococcus aureus $(S$. aureus) infections are generally classified as being caused by methicillin-resistant $S$. aureus (MRSA) or methicillin-susceptible $S$. aureus (MSSA). While the prevalence of MRSA bloodstream infections is relatively low, the proportion of surgical site infections caused by MRSA has substantially increased over the past 15 years and is associated with alarming mortality rates in neutropenic, adult cancer patients [2, 22]. It has also been demonstrated that both MSSA and MRSA infections in non-neutropenic, cancer patients are serious clinical conditions frequently associated with the placement of a central venous catheter or an indwelling urinary catheter [14]. Various reviews suggest that $S$. aureus is responsible for $1.3-12 \%$ of bacteremia cases, $27 \%$ of skin and soft tissue infections, and
$26 \%$ of pneumonia infections in cancer patients $[14,15,22]$. Antibiotic treatment of $S$. aureus infections differs between MSSA and MRSA infections. Anti-staphylococcal beta-lactam antibiotics, including cefazolin or nafcillin, should be used to control invasive MSSA infections [21]. Vancomycin remains the antibiotic of choice to combat MRSA; however, limited studies of daptomycin in cancer patients are promising [23, 24]. Vancomycin should be avoided in patients with MSSA bacteremia due to its high mortality compared to treatment of MSSA with beta-lactam antibiotics [25]. In addition to antibiotic therapy, patients with bloodstream infections caused by $S$. aureus should undergo central venous catheter removal [26]. Members of the Streptococcus species can give rise to infection in cancer patients via multiple routes, and the most common culprits are viridans group streptococci (VGS), beta-hemolytic streptococci, and Streptococcus pneumoniae $(S$. pneumoniae) [16]. Each of these organisms may be isolated from invasive diagnostic procedures in patients with post-obstructive pneumonia [2]. Moreover, VGS and S. pneumoniae colonize mucosal surfaces damaged by cancer chemotherapy, thereby increasing the risk of infection [2]. VGS bacteremia is common among neutropenic patients and while relatively mild in most instances, a portion of cancer patients will go on to develop VGS shock syndrome and face high mortality rates [17, $27,28]$. Multidrug resistance is a challenge when considering optimal treatment for VGS as many strains are non-susceptible to fluoroquinolones and beta-lactam antibiotics [29]. One study suggests that while VGS susceptibility rate to cefepime was found to be significantly higher in adults than children, cefepime susceptibility did not impact clinical outcome [29]. More studies are needed to define optimal VGS therapy.

Invasive disease due to beta-hemolytic streptococci, specifically Streptococcus agalactiae ( $S$. agalactiae), is also common in cancer patients [21]. In one study, S. agalactiae was most commonly detected in adult patients with solid tumors with indwelling medical devices or who underwent surgical procedures [30]. S. agalactiae-related mortality rates were highest in patients with neoplastic gastrointestinal disease $(46 \%)$ and lowest in patients with neoplastic genitourinary disease (3\%) [30]. Another study identified a significant increase in the rates of $S$. agalactiae bloodstream infection in patients with breast cancer or tissue/bone sources of streptococcal bloodstream infections [16]. Cephalosporins and penicillins remain the antibiotics of choice for treating $S$. agalactiae despite an increase in penicillin-resistance due to vaccination approaches [31, 32]. Cancer patients with active leukemia, lymphoma or myeloma are at the highest risk for developing an invasive disease due to $S$. pneumoniae [33]. Pneumonia is the most common source of pneumococcal bacteremia, and a respiratory source of infection is a risk factor for developing severe disease $[16,18]$. While invasive $S$. pneumoniae infections in cancer patients are commonly caused by serotypes covered by pneumococcal vaccines, immunocompromised patients are at greater risk for developing invasive pneumococcal disease caused by nonvaccine covered serotypes [34]. In vitro pneumococcal susceptibility tests suggest $S$. pneumoniae in the USA remains susceptible to levofloxacin and vancomycin; however, the connection between susceptibility and therapeutic success is unclear [21]. 
Table 1. Common Infections in Cancer Patients, Frequency and Treatment

\begin{tabular}{|c|c|c|}
\hline Organism & Frequency & Treatment \\
\hline \multirow[t]{2}{*}{ S. aureus } & Between $1.3 \%$ and $12 \%$ of bacteremia cases [15] & $\begin{array}{l}\text { Methicillin-susceptible } S \text {. aureus should be treated with an } \\
\text { anti-staphylococcal beta-lactam (i.e., cefazolin or nafcillin). }\end{array}$ \\
\hline & About $26 \%$ of pneumonia cases [14] & Venous catheter removal recommended \\
\hline $\begin{array}{l}\text { Viridans group } \\
\text { streptococci }\end{array}$ & $\begin{array}{l}\text { Occurred in about } 23 \% \text { of children with AML } \\
\text { being treated with chemotherapy [17] }\end{array}$ & No well-defined, optimal therapy \\
\hline S. agalactiae & $\begin{array}{l}\text { Accounts for }>80 \% \text { of recurrent infections following } \\
\text { streptococcal bloodstream infections [16] }\end{array}$ & Treat with penicillins or cephalosporins \\
\hline S. pneumoniae & Accounts for about $6.5 \%$ of episodes of bacteremia [18] & Treat with levofloxacin or vancomycin \\
\hline Enterococcus species & $\begin{array}{l}\text { Disproportionately found in cancer patients; } \\
15-20 \% \text { are vancomycin resistant. }\end{array}$ & $\begin{array}{l}\text { Vancomycin resistant Enterococcus should } \\
\text { be treated with daptomycin or linezolid }\end{array}$ \\
\hline E. coli & Associated mortality is over $15 \%$ & \\
\hline Klebsiella species & $\begin{array}{l}\text { Klebsiella pneumoniae carbapenemase- } \\
\text { producing K. pneumonia, greater than } 70 \% \\
\text { mortality for bacteremic infections }\end{array}$ & Treat with tigecycline and piperacillin/tazobactam \\
\hline P. aeruginosa & Declining prevalence secondary to antibiotic coverage & $\begin{array}{l}\text { Treat with piperacillin/tazobactam and } \\
\text { venous catheter removal recommended }\end{array}$ \\
\hline \multirow[t]{2}{*}{ Candida species } & Incidence varies widely across studies & $\begin{array}{l}\text { Treat with fluconazole. May also offer fluconazole } \\
\text { prophylaxis for highest risk patients. }\end{array}$ \\
\hline & $\begin{array}{l}\text { Patients with acute leukemia are at the highest } \\
\text { risk for developing invasive candidiasis during } \\
\text { episodes of post-chemotherapy neutropenia }\end{array}$ & \\
\hline $\begin{array}{l}\text { Community-acquired } \\
\text { respiratory viruses }\end{array}$ & $\begin{array}{l}\text { The risk for infection via CARVs mirrors respiratory } \\
\text { virus outbreaks in the general population [19]. The } \\
\text { degree, duration, and type of immunosuppression } \\
\text { at patient are receiving directly correlates to } \\
\text { the severity of CARV infections [20]. }\end{array}$ & Supportive care \\
\hline
\end{tabular}

S. aureus: Staphylococcus aureus; AML: acute myeloid leukemia; S. agalactiae: Streptococcus agalactiae; S. pneumoniae: Streptococcus pneumoniae; E. faecalis: Enterococcus faecalis; E. coli: Escherichia coli; P. aeruginosa: Pseudomonas aeruginosa; HSV: herpes simplex virus; CARVs: community-acquired respiratory viruses.

Enterococci infections are disproportionately found in cancer patients and are challenging to treat [35]. Enterococcus faecium (E. faecium) and Enterococcus faecalis (E. faecalis) cause bacteremia in cancer patients and have been linked to nosocomial infection onset, prior antibiotic exposure, and prolonged neutropenia [36]. Nearly $15-20 \%$ of Enterococcus species are vancomycin-resistant (VRE) and are linked to poorer clinical outcomes [2]. High VRE levels in cancer patients' stool may predict subsequent bacteremia [37]. While more studies are needed to determine the optimal therapy for VRE bacteremia; daptomycin and linezolid are currently the most widely used antimicrobials for this condition [38]. E. faecium strains in cancer patients are similarly difficult to treat due to universal betalactam resistance and increasing vancomycin resistance [37]. $E$. faecalis isolates that retain penicillin susceptibility should be treated with the appropriate beta-lactam antibiotic [21]. 


\section{Gram-negative bacteria}

Gram-negative bloodstream infections are more common than gram-positive bloodstream infections in cancer patients with solid tumors [13]. The lower incidence of gram-negative infections in patients with hematologic malignancies can be attributed to the antibiotic prophylaxis many receive following chemotherapy treatment; however, the number of antibioticresistant strains is steadily increasing [2, 39]. Additionally, some studies suggest that gram-negative bacteria may facilitate tumor progression and support tumor metastasis [40, 41]. The most commonly isolated gram-negative organisms include: Escherichia coli, Klebsiella species, and Pseudomonas aeruginosa ( $P$. aeruginosa) [42]. These organisms commonly colonize the urinary tract following urinary stasis and can lead to the development of complicated urinary tract infections, urosepsis, or bacteremia [43]. Escherichia coli (E. coli) has historically been the most common gram-negative species to cause infection in neutropenic cancer patients [44]. One study of bacteremia in cancer patients described nearly $21 \%$ of gramnegative bacteremia cases were attributed to $E$. coli infection, and the associated mortality was $17 \%$ [45]. Of increasing concern is the prevalence of quinolone-resistant $E$. coli which disproportionately affects neutropenic cancer patients who have received prophylactic quinolone treatment [46, 47]. Underlying malignancy and immunosuppressive therapy contribute to the more severe disease and higher fatality rate seen in cancer patients that acquire E. coli infections [48]. E. coli strains that produce extended-spectrum beta-lactamase (ESBL) should be preferentially treated with carbapenems including meropenem or imipenem [49]. In cases of complicated urinary tract infection caused by $E$. coli, plazomicin shows similar clinical cure rates as meropenem and may be used as an alternative for patients who cannot tolerate carbapenems [50].

Klebsiella species are prevalent pathogens in healthcare-associated infections, and multidrug resistant strains pose a challenge to cancer patients with neutropenia [51]. Most infections associated with Klebsiella species are urinary tract infections or primary blood stream infections while all Klebsiella species infections in cancer patients are associated with high mortality related to acute infection. One particular strain of Klebsiella pneumoniae (K. pneumoniae) called Klebsiella pneumoniae carbapenemase-producing $K$. pneumoniae has been identified to have greater than $70 \%$ mortality for bacteremic infections [51]. As the prevalence of carbapenem-resistant K. pneumonia increases, tigecycline in combination with piperacillin/ tazobactam seems to be a promising treatment [52]. Clinical experience with prolonged ceftazidime-avibactam infusion to treat carbapenem-resistant $K$. pneumonia is limited, but studies show a carbapenem can be added if the isolate has an elevated minimum inhibitory concentration to ceftazidime-avibactam [53]. . aeruginosa is another gram-negative organism with growing resistance that causes infection in cancer patients. Prophylactic antibiotics and empiric antibiotic coverage has led to a decline in the prevalence of microbiologically proven $P$. aeruginosa infections in cancer patients [54]. However, rapidly progressive pseudomonas infections can be severe and are best treated when the appropriate therapy is quickly initiated in high-risk patients. Antipseudomonal beta-lactam agents, specifically piperacillin-tazobactam, should be used as monotherapy at cancer centers with low rates of resistance [26]. In addition to antibiotic therapy, venous catheters should be removed in patients with bloodstream infections caused by $P$. aeruginosa [26].

\section{Fungi}

Cancer patients who have experienced neutropenic episodes lasting longer than 7 - 10 days are at the greatest risk of developing a fungal infection [7]. Fungal infections are linked with polymicrobial catheter-related infections; however, they can also rarely lead to bloodstream infections [2]. The use of prophylaxis targeting Candida species in patients with hematologic malignancies has led the incidence of Aspergillus infections to surpass that of Candida infections [55]. Reports of infections with Fusarium species and Scedosporium species isolates have also been made in patients with hematologic malignancies [56, 57]. Candida species lead to the most invasive yeast infections in cancer patients [58]. Cytotoxic chemotherapy compromises the mucosal surfaces upon which Candida typically thrives, and these commensal organisms commonly enter the body through the gastrointestinal tract in cancer patients [58]. While the incidence of invasive candidiasis in cancer patients has varied widely across various studies, patients with acute leukemia are at the highest risk for developing invasive candidiasis during episodes of post-chemotherapy neutropenia [59]. Candida albicans accounts for over $50 \%$ of Candida infections; however, patients with hematologic malignancies are also at an increased risk of developing non-albicans Candida species infections compared to immunocompetent patients [59]. While Candida prophylaxis with fluconazole in high-risk patients has decreased the incidence of infection, breakthrough infections, resistance to fluconazole, and cross-resistance to any azole have all been reported $[60,61]$. Aspergillus is the most common fungal organism in patients with hematologic malignancies [62]. This airborne organism is usually causes pneumonia after being inhaled into the sinuses and respiratory tract. While Aspergillus fumigatus (A. fumigatus) is the most common Aspergillus species to cause disease, several others may lead to invasive disease [63]. Reports suggest invasive aspergillosis has an incidence of $4-15 \%$ and a mortality of $60-85 \%$ [64]. In addition to azoles, antifungal treatment against Aspergillus infections includes caspofungin and other echinocandins [65]. However, it is important to note there have been reports of caspofungin failing to prevent aspergillosis [66]. Antifungal susceptibility testing should be considered for all patients with breakthrough mold infection [67].

\section{Viruses}

While viruses are common in patients with chemotherapy-induced neutropenia, antiviral prophylaxis can be used to reduce the risk of infection [68]. Despite prophylaxis viral reactivation in cancer patients is possible as a result of immunosuppres- 
sion. Common viral infections in cancer patients include: herpes simplex virus (HSV)-1 and 2, varicella zoster virus (VZV), and community-acquired respiratory viruses (CARVs). Cancer patients are at an increased risk of HSV-1 and -2 reactivations, both of which are influenced by the dose and duration of cytotoxic chemotherapy treatment [69]. Two-thirds of seropositive patients who undergo induction chemotherapy for acute myeloid leukemia will experience reactivation [70]. Similarly, patients who undergo hematopoietic cell transplantation (HCT) without receiving antiviral prophylaxis are at an increased risk for activation [71]. Oral mucositis lesions in populations of chemotherapy and bone marrow transplant patients should be evaluated for HSV [69]. Generally, culture positive lesions are more severe than culture negative ones [69]. Aggressive treatment with acyclovir should be initiated following laboratory testing, and seropositive leukemia patients should be recommended for acyclovir prophylaxis [69]. Immunocompromised patients receiving malignancy-related therapy are at an increased risk of VZV reactivation and infection [72]. Reactivation of VZV causes herpes zoster in an average of 5 months following the initiation of chemotherapy in lymphoma patients [73]. VZV reactivation and subsequent infection has also been reported following radiotherapy in patients with breast cancer [74]. Disseminated herpes zoster infection has been reported in recipients of autologous and allogeneic hematopoietic stem cell transplantation in highly immunocompromised [75]. Important to note is that the main risk factor for VZV reactivation is a disrupted cellular immune response, not the severity of neutropenia [75]. Prophylactic acyclovir should be considered in patients with an extended duration of low lymphocyte count or long-term steroid use to prevent the poor clinical course associated with visceral disseminated VZV infection [75].

CARVs occur at a higher frequency and pose a significant threat to neutropenic patients [76]. The risk for infection via CARVS mirrors respiratory virus outbreaks in the general population [19]. The degree, duration, and type of immunosuppression at patient are receiving directly correlates to the severity of CARV infections [20]. CARV infections include influenza viruses, parainfluenza viruses types I - IV, human adenovirus, human rhinoviruses, human metapneumovirus, respiratory syncytial virus, and human coronaviruses. Limited information about the novel, severe acute respiratory syndrome coronavirus 2 (SARS-CoV-2), the virus that causes coronavirus disease 2019 (COVID-19), has been released. However, early reports suggest COVID-19 severity may be worse in cancer patients, specifically in those with additional comorbidities [77]. COVID-19 infection is a direct threat to immunocompromised cancer patients, and the pandemic has impacted the management of cancer. From early on, the pandemic has overwhelmed the healthcare system and caused diagnostic testing and procedures to be postponed [78]. Patient fears of contracting COVID-19 may have further delayed critical doctor's appointments, further worsening the outcome of cancers with stage-dependent prognosis [79]. For previously established cancer patients, healthcare providers and patients have had to weigh the risks and benefits of cancer management throughout the pandemic. Shorter appointment times and decreased follow-up frequency have significantly impacted how cancers have been diagnosed and treated since the start of the pandemic [80]. The use of telemedicine has provided a safe, convenient alternative to in-person appointments for cancer patients during the pandemic, and improving this platform will be critical in the setting of future public health crisis [80].

\section{Treatment Recommendations}

It is known that cytotoxic chemotherapy can induce prolonged periods of severe neutropenia during which patients are at an increased risk for developing complications secondary to infections. In order to reduce infectious complications, various societies have put forth recommendations for antibacterial, antifungal, and antiviral prophylaxis. This section will explore recommendations provided by American Society of Clinical Oncology (ASCO), Infectious Diseases Society of America (IDSA) Fever and Neutropenia Guidelines, and National Comprehensive Cancer Network (NCCN).

\section{Antibacterial prophylaxis}

Antibacterial prophylaxis typically targets virulent gram-negative bacilli, including $P$. aeruginosa, which may cause lifethreatening infections in patients. Fluoroquinolones are the antibiotics of choice referenced in most guidance for prophylaxis in cancer patients since they have been extensively studied [26]. Some known risks with fluoroquinolone use in patients at risk for developing neutropenic fever include QT prolongation, growing antibiotic resistance, and increasing Clostridioides difficile infections [81, 82]. Antibacterial guidance is generally categorized by risk stratification for developing complications secondary to neutropenia: high-risk, intermediate-risk, and low-risk. Guidance from the ASCO and IDSA Fever and Neutropenia Guidelines recommend that high-risk patients (those with an absolute neutrophil count of $\leq 100$ cells $/ \mathrm{mm}^{3}$ for $>7$ days) who do not otherwise have a contraindication to receiving a fluoroquinolone should receive fluoroquinolone prophylaxis $[26,83]$. Similarly, NCCN guidelines recommend fluoroquinolone prophylaxis for patients their society classifies as high-risk, including: patients undergoing allogeneic hematopoietic transplant, neutropenic patients receiving induction chemotherapy for acute leukemia, and patients in which the anticipated duration of neutropenia is $>10$ days [48]. NCCN also extends the consideration of fluoroquinolone prophylaxis to intermediate-risk groups including those with autologous hematopoietic transplant, lymphoma, multiple myeloma, chronic lymphocytic leukemia, purine analog therapy, or anticipated neutropenia between 7 - 10 days [48]. Levofloxacin and ciprofloxacin are the most studied, and levofloxacin is favored in patients at increased risk for Streptococcus viridans mucositis [26]. Guidance from aforementioned societies suggests that for intermediate-risk patients, those who can expect 7 - 10 days of neutropenia secondary to cancer treatment, decisions to give a fluoroquinolone must be evaluated on a case-by-case basis. A thorough risk-benefit analysis should be performed for each patient of intermediate risk. According to NCCN, patients who generally fall into this risk category 
include autologous HCT recipients, patients with lymphoma, chronic lymphocytic leukemia or multiple myeloma [48]. For low-risk patients who can anticipate neutropenia of 7 days or fever, neither the ASCO nor the IDSA recommend routine use of fluoroquinolone-based antibacterial prophylaxis [83]. Studies suggest that for low-risk patients, there is a high number needed to treat in order to prevent a single infection [84]. Lowrisk patients generally include those with solid tumors being treated with conventional chemotherapy.

\section{Antifungal prophylaxis}

Invasive fungal infections (i.e., candidemia) and Pneumocystis pneumonia (PCP) are complications faced by those with hematologic malignancies and HCT recipients. Of note, current controversy with regards to antifungal prophylaxis focuses on local rates of resistance and overall risks of invasive fungal infections based on antineoplastic agent.

Antimicrobial prophylaxis guidelines released by ASCO and IDSA in 2018 and aspergillosis management guidelines released by IDSA in 2016 suggest that antifungal prophylaxis is recommended for patients in which the anticipated duration of severe neutropenia is greater than 7 days $[83,85]$. Per the guidelines, antifungal agents should be selected based on the type of chemotherapy and anticipated adverse effects. For example, fluconazole is the antifungal of choice for patients undergoing initial induction or salvage chemotherapy who are likely to develop oral or gastrointestinal mucositis [83, 85]. On the other hand, posaconazole or voriconazole are the preferred antifungal agents for patients subject to invasive mold infections and Candida species secondary to intensive chemotherapy for acute myelogenous leukemia or advanced myelodysplastic syndrome $[83,85]$. These guidelines do not recommend antifungal prophylaxis for patients with solid tumors or lymphoma who are undergoing conventional chemotherapy without concomitant immunotherapies [26].

The NCCN has also published guidelines for the use of PCP prophylaxis of trimethoprim-sulfamethoxazole in patients with cancer as well as those who have undergone HCT [48]. Patients with a PCP risk factor greater than $6 \%$ should start PCP prophylaxis. Patients who are most susceptible include: patients with another cause of immunocompromise who are also receiving glucocorticoids for an extended period of time, patients receiving alemtuzumab, patients receiving concomitant temozolomide and radiotherapy, patients with acute lymphocytic leukemia, allogeneic HCT recipients, and select autologous HCT recipients [48].

\section{Antiviral prophylaxis}

Viral infection and reactivation are complications that may arise in the setting of neutropenia. Guidelines for antiviral prophylaxis rely both on vaccines and antiviral medications to protect neutropenic patients. Influenza infection follows predictable patterns as seasons change, and the annual influenza vaccine is a tool readily available for neutropenic patients to reduce the chance of infection. ASCO and IDSA recommend annual immunization with an inactive influenza vaccine for all patients receiving cancer treatment [83]. Timing is critical, and ideally, the vaccine is given at least 2 weeks before initiating chemotherapy or following the completion of treatment [83]. Moreover, in the circumstance that the patient is a resident of a long-term care facility, chemoprophylaxis to prevent influenza virus is indicated [86]. HSV and VZV reactivation occurs in patients who are not receiving prophylaxis, and they are significant causes of morbidity in neutropenic patients. Per ASCO and IDSA guidelines, acyclovir or valacyclovir prophylaxis is indicated in patients seropositive for HSV who are undergoing allogeneic HCT or induction chemotherapy of acute leukemia [26]. Baseline duration of HSV and VZV prophylaxis differs; however, treatment of either virus may be extended in the setting of graft-versus-host disease for patients who are HCT recipients [26]. Hepatitis B reactivation with a flare of hepatitis may lead to hepatic failure in patients receiving chemotherapy. Patients with elevated circulating hepatitis B DNA, detectable hepatitis B surface antigen or those who have been infected and cleared the virus and developed a hepatitis B surface antigen or core antibody are all at risk. ASCO and IDSA guidelines recommend entecavir or tenofovir as nucleoside reverse transcriptase inhibitors that should be given to patients at risk of reactivation [83].

\section{Interactions Between Antibiotics and Cancer Therapy}

While antibiotics are critical agents for treating bacterial infections in cancer patients, some have the capacity to interact with various cancer therapies, thus inhibiting their anticancer effects. In patients receiving radiotherapy, antibiotics may weaken the immune response and affect the metabolism of normal tissues $[87,88]$. This metabolic disturbance has a synergistic effect with the destruction of normal tissues in radiotherapy [89]. Antibiotics may also lead to chronic inflammation in combination with chemotherapy, thus disrupting the intestinal microbiota and inhibiting the chemotherapeutic treatment of cancers [90]. Tetracyclines have received specific attention for their inhibition of T-lymphocytes and stimulation of PGE2 production, leading to an overall increased cancerogenic and metastatic potential $[91,92]$. Similarly, studies show that antibiotics can inhibit the effects of immunotherapy for cancer with immunotoxicity, genotoxicity or cytotoxicity via disruptions to the intestinal microbiota [93]. Disordered intestinal flora also explains the mechanism by which antibiotics weaken the therapeutic effect of immune checkpoint inhibitors [89]. Moreover, it has been demonstrated that long-term antibiotic use has a greater impact on checkpoint inhibitor efficacy that short-term use [94].

Of note, some antibiotics have been shown to have anticancer effects. For example, clioquinol, a metal chelator, was used as an antimicrobial agent for many years. It is known that metals are important in both carcinogenesis an angiogenesis $[95,96]$. Clioquinol has been shown to inhibit the activity of the enzyme SOD1, a critical target for anticancer therapy, by binding metals essential for its function: copper and zinc 
$[97,98]$. The anticancer effects of clioquinol have been demonstrated both in vitro as well as in vivo [97]. Ampicillin is another antibiotic that has received some attention for its potential anticancer effects. In vitro studies have suggested ampicillin in various combinations may have an antitumor effect in colorectal cancer and irritating effects at a vascular level $[99,100]$. While some studies suggest that the aforementioned tetracycline increase metastatic potential, others show this antibiotic has dose- and time-dependent cytotoxic effects [100]. In colorectal adenocarcinoma cell line HT-29, tetracycline has decreased cell viability and inhibited cell migration [100]. Overall, in vitro studies will serve as the basis for further exploring the interactions between antibiotics and cancer therapies as well as the anticancer effects of some antibiotics.

\section{Conclusions}

While the relationship between infections and cancer is complex, there are evolving treatment modalities to protect vulnerable cancer patients, particularly those with severe neutropenia. There are several factors that make a patient more or less susceptible to an infection. Some factors are directly related to the cancer they have whereas others are dependent on comorbidities or social factors. Given the wide variety of infection sources in cancer patients, it is critical to understand infections which are more likely based on susceptibilities and anatomical considerations to treat appropriately. It is also important to remember that even infection control may come at a cost. When taken in combination with radiation therapy, chemotherapy or immunotherapy, some antibiotics may increase the risk of systemic inflammation and metastatic potential. In order to help navigate the risks and benefits of treating and protecting against infections in cancer patients, guidelines have been established for the care of the neutropenic patient. These guidelines are easily accessible and provide clear recommendations based on the specific infection and risk stratification of the patient. Overall, there is a wealth of knowledge that exists to guide the treatment of infections in cancer patients. As our understanding of infection control and cancer therapies continues to evolve, guidelines will be expected to change accordingly in an effort to protect our most vulnerable patients from infections that may complicate their clinical course.

\section{Acknowledgments}

None to declare.

\section{Financial Disclosure}

None to declare.

\section{Conflict of Interest}

The authors declare no competing financial interests.

\section{Author Contributions}

Amanda Delgado and Achuta Kumar Guddati: study design, data analysis, and manuscript writing. Both authors have read the manuscript and agree to the content.

\section{Data Availability}

The authors declare that data supporting the findings of this study are available within the article.

\section{References}

1. Oh JK, Weiderpass E. Infection and cancer: global distribution and burden of diseases. Ann Glob Health. 2014;80(5):384-392.

2. Rolston KV. Infections in cancer patients with solid tumors: a review. Infect Dis Ther. 2017;6(1):69-83.

3. Abers MS, Sandvall BP, Sampath R, Zuno C, Uy N, Yu VL, Stager CE, et al. Postobstructive pneumonia: an underdescribed syndrome. Clin Infect Dis. 2016;62(8):957961.

4. Bin Nafisah S, Ahmad M. Ommaya reservoir infection rate: a 6-year retrospective cohort study of Ommaya reservoir in pediatrics. Childs Nerv Syst. 2015;31(1):29-36.

5. Rusu RA, Sirbu D, Curseu D, Nasui B, Sava M, Vesa SC, Bojan A, et al. Chemotherapy-related infectious complications in patients with hematologic malignancies. J Res Med Sci. 2018;23:68.

6. Glimelius I, Diepstra A. Novel treatment concepts in Hodgkin lymphoma. J Intern Med. 2017;281(3):247-260.

7. Nesher L, Rolston KV. The current spectrum of infection in cancer patients with chemotherapy related neutropenia. Infection. 2014;42(1):5-13.

8. Sawyers C. Targeted cancer therapy. Nature. 2004;432(7015):294-297.

9. Yaghmour G, Pandey M, Ireland C, Patel K, Nunnery S, Powell D, Baum S, et al. Role of genomic instability in immunotherapy with checkpoint inhibitors. Anticancer Res. 2016;36(8):4033-4038.

10. Topalian SL, Sznol M, McDermott DF, Kluger HM, Carvajal RD, Sharfman WH, Brahmer JR, et al. Survival, durable tumor remission, and long-term safety in patients with advanced melanoma receiving nivolumab. J Clin Oncol. 2014;32(10):1020-1030.

11. Atkins $\mathrm{S}, \mathrm{He} \mathrm{F}$. Chemotherapy and Beyond: Infections in the Era of Old and New Treatments for Hematologic Malignancies. Infect Dis Clin North Am. 2019;33(2):289309.

12. Sui JD, Wang Y, Wan Y, Wu YZ. Risk of hematologic toxicities with programmed cell death-1 inhibitors in cancer patients: a meta-analysis of current studies. Drug Des Devel Ther. 2018;12:1645-1657.

13. Marin M, Gudiol C, Garcia-Vidal C, Ardanuy C, Carratala J. Bloodstream infections in patients with solid tumors: epidemiology, antibiotic therapy, and outcomes in 528 
episodes in a single cancer center. Medicine (Baltimore). 2014;93(3):143-149.

14. Kang CI, Song JH, Ko KS, Chung DR, Peck KR, Asian Network for Surveillance of Resistant Pathogens Study G. Clinical features and outcomes of Staphylococcus aureus infections in non-neutropenic cancer patients. Support Care Cancer. 2012;20(3):483-488.

15. Montassier E, Batard E, Gastinne T, Potel G, de La Cochetiere MF. Recent changes in bacteremia in patients with cancer: a systematic review of epidemiology and antibiotic resistance. Eur J Clin Microbiol Infect Dis. 2013;32(7):841-850.

16. Shelburne SA, 3rd, Tarrand J, Rolston KV. Review of streptococcal bloodstream infections at a comprehensive cancer care center, 2000-2011. J Infect. 2013;66(2):136146.

17. Lewis V, Yanofsky R, Mitchell D, Dix D, Ethier MC, Gillmeister B, Johnston D, et al. Predictors and outcomes of viridans group streptococcal infections in pediatric acute myeloid leukemia: from the Canadian infections in AML research group. Pediatr Infect Dis J. 2014;33(2):126-129.

18. Garcia-Vidal C, Ardanuy C, Gudiol C, Cuervo G, Calatayud L, Bodro M, Duarte R, et al. Clinical and microbiological epidemiology of Streptococcus pneumoniae bacteremia in cancer patients. J Infect. 2012;65(6):521-527.

19. Bresee J, Hayden FG. Epidemic influenza-responding to the expected but unpredictable. N Engl J Med. 2013;368(7):589-592.

20. Englund JA, Whimbey E, Atmar RL. Diagnosis of respiratory viruses in cancer and transplant patients. Curr Clin Top Infect Dis. 1999;19:30-59.

21. Holland T, Fowler VG, Jr., Shelburne SA, 3rd. Invasive gram-positive bacterial infection in cancer patients. Clin Infect Dis. 2014;59(Suppl 5):S331-334.

22. Li Z, Zhuang H, Wang G, Wang H, Dong Y. Prevalence, predictors, and mortality of bloodstream infections due to methicillin-resistant Staphylococcus aureus in patients with malignancy: systemic review and meta-analysis. BMC Infect Dis. 2021;21(1):74.

23. Rolston KV, Besece D, Lamp KC, Yoon M, McConnell SA, White P. Daptomycin use in neutropenic patients with documented gram-positive infections. Support Care Cancer. 2014;22(1):7-14.

24. Mahajan SN, Shah JN, Hachem R, Tverdek F, Adachi JA, Mulanovich V, Rolston KV, et al. Characteristics and outcomes of methicillin-resistant staphylococcus aureus bloodstream infections in patients with cancer treated with vancomycin: 9-year experience at a comprehensive cancer center. Oncologist. 2012;17(10):1329-1336.

25. Kim SH, Kim KH, Kim HB, Kim NJ, Kim EC, Oh MD, Choe KW. Outcome of vancomycin treatment in patients with methicillin-susceptible Staphylococcus aureus bacteremia. Antimicrob Agents Chemother. 2008;52(1):192197.

26. Freifeld AG, Bow EJ, Sepkowitz KA, Boeckh MJ, Ito JI, Mullen CA, Raad, II, et al. Clinical practice guideline for the use of antimicrobial agents in neutropenic patients with cancer: 2010 update by the infectious diseases society of america. Clin Infect Dis. 2011;52(4):e56-93.
27. Dulanto Chiang A, Sinaii N, Palmore TN. Risk Factors for Viridans Group Streptococcal Bacteremia in Neutropenic and Non-neutropenic Patients: A Single Center Case-Case-Control Study. Open Forum Infect Dis. 2018;5(1):ofx260.

28. Dix D, Cellot S, Price V, Gillmeister B, Ethier MC, Johnston DL, Lewis V, et al. Association between corticosteroids and infection, sepsis, and infectious death in pediatric acute myeloid leukemia (AML): results from the Canadian infections in AML research group. Clin Infect Dis. 2012;55(12):1608-1614.

29. Han SB, Bae EY, Lee JW, Lee DG, Chung NG, Jeong DC, Cho B, et al. Clinical characteristics and antimicrobial susceptibilities of viridans streptococcal bacteremia during febrile neutropenia in patients with hematologic malignancies: a comparison between adults and children. BMC Infect Dis. 2013;13:273.

30. Pimentel BA, Martins CA, Mendonca JC, Miranda PS, Sanches GF, Mattos-Guaraldi AL, Nagao PE. Streptococcus agalactiae infection in cancer patients: a five-year study. Eur J Clin Microbiol Infect Dis. 2016;35(6):927933.

31. Phares CR, Lynfield R, Farley MM, Mohle-Boetani J, Harrison LH, Petit S, Craig AS, et al. Epidemiology of invasive group B streptococcal disease in the United States, 1999-2005. JAMA. 2008;299(17):2056-2065.

32. Richter SS, Heilmann KP, Dohrn CL, Riahi F, Diekema DJ, Doern GV. Pneumococcal serotypes before and after introduction of conjugate vaccines, United States, 19992011(1.). Emerg Infect Dis. 2013;19(7):1074-1083.

33. Domenech A, Ardanuy C, Grau I, Calatayud L, Pallares R, Fenoll A, Brueggemann AB, et al. Evolution and genetic diversity of the Spain23F-ST81 clone causing adult invasive pneumococcal disease in Barcelona (19902012). J Antimicrob Chemother. 2014;69(4):924-931.

34. Lujan M, Burgos J, Gallego M, Falco V, Bermudo G, Planes A, Fontanals D, et al. Effects of immunocompromise and comorbidities on pneumococcal serotypes causing invasive respiratory infection in adults: implications for vaccine strategies. Clin Infect Dis. 2013;57(12):17221730 .

35. Vydra J, Shanley RM, George I, Ustun C, Smith AR, Weisdorf DJ, Young JA. Enterococcal bacteremia is associated with increased risk of mortality in recipients of allogeneic hematopoietic stem cell transplantation. Clin Infect Dis. 2012;55(6):764-770.

36. Gudiol C, Ayats J, Camoez M, Dominguez MA, Garcia-Vidal $\mathrm{C}$, Bodro $\mathrm{M}$, Ardanuy $\mathrm{C}$, et al. Increase in bloodstream infection due to vancomycin-susceptible Enterococcus faecium in cancer patients: risk factors, molecular epidemiology and outcomes. PLoS One. 2013;8(9):e74734.

37. Kang Y, Vicente M, Parsad S, Brielmeier B, Pisano J, Landon E, Pettit NN. Evaluation of risk factors for vancomycin-resistant Enterococcus bacteremia among previously colonized hematopoietic stem cell transplant patients. Transpl Infect Dis. 2013;15(5):466-473.

38. Whang DW, Miller LG, Partain NM, McKinnell JA. Systematic review and meta-analysis of linezolid and dapto- 
mycin for treatment of vancomycin-resistant enterococcal bloodstream infections. Antimicrob Agents Chemother. 2013;57(10):5013-5018.

39. Lee JH, Kim SK, Kim SK, Han SB, Lee JW, Lee DG, Chung $\mathrm{NG}$, et al. Increase in antibiotic-resistant gramnegative bacterial infections in febrile neutropenic children. Infect Chemother. 2016;48(3):181-189.

40. Sun M, Bai Y, Zhao S, Liu X, Gao Y, Wang L, Liu B, et al. Gram-negative bacteria facilitate tumor progression through TLR4/IL-33 pathway in patients with non-smallcell lung cancer. Oncotarget. 2018;9(17):13462-13473.

41. Ye M, Gu X, Han Y, Jin M, Ren T. Gram-negative bacteria facilitate tumor outgrowth and metastasis by promoting lipid synthesis in lung cancer patients. J Thorac Dis. 2016;8(8):1943-1955.

42. Marin M, Gudiol C, Ardanuy C, Garcia-Vidal C, Calvo M, Arnan M, Carratala J. Bloodstream infections in neutropenic patients with cancer: differences between patients with haematological malignancies and solid tumours. J Infect. 2014;69(5):417-423.

43. Bahu R, Chaftari AM, Hachem RY, Ahrar K, Shomali W, El Zakhem A, Jiang Y, et al. Nephrostomy tube related pyelonephritis in patients with cancer: epidemiology, infection rate and risk factors. J Urol. 2013;189(1):130135 .

44. Trecarichi EM, Tumbarello M. Antimicrobial-resistant Gram-negative bacteria in febrile neutropenic patients with cancer: current epidemiology and clinical impact. Curr Opin Infect Dis. 2014;27(2):200-210.

45. Krcmery V, Spanik S, Mrazova M, Trupl J, Grausova S, Grey E, Kukuckova E, et al. Bacteremias caused by Escherichia coli in cancer patients - analysis of 65 episodes. Int J Infect Dis. 2002;6(1):69-73.

46. Yoo JH, Huh DH, Choi JH, Shin WS, Kang MW, Kim $\mathrm{CC}$, Kim DJ. Molecular epidemiological analysis of quinolone-resistant Escherichia coli causing bacteremia in neutropenic patients with leukemia in Korea. Clin Infect Dis. 1997;25(6):1385-1391.

47. Zhu DM, Li QH, Shen Y, Zhang Q. Risk factors for quinolone-resistant Escherichia coli infection: a systematic review and meta-analysis. Antimicrob Resist Infect Control. 2020;9(1):11.

48. https://www.nccn.org/patients/guidelines/content/PDF/ anemia-patient-guideline.pdf.

49. Tamma PD, Han JH, Rock C, Harris AD, Lautenbach E, Hsu AJ, Avdic E, et al. Carbapenem therapy is associated with improved survival compared with piperacillin-tazobactam for patients with extended-spectrum beta-lactamase bacteremia. Clin Infect Dis. 2015;60(9):1319-1325.

50. Wagenlehner FME, Cloutier DJ, Komirenko AS, Cebrik DS, Krause KM, Keepers TR, Connolly LE, et al. OnceDaily Plazomicin for Complicated Urinary Tract Infections. N Engl J Med. 2019;380(8):729-740.

51. Freire MP, Pierrotti LC, Filho HH, Ibrahim KY, Magri AS, Bonazzi PR, Hajar L, et al. Infection with Klebsiella pneumoniae carbapenemase (KPC)-producing Klebsiella pneumoniae in cancer patients. Eur J Clin Microbiol Infect Dis. 2015;34(2):277-286.

52. Bucaneve G, Micozzi A, Picardi M, Ballanti S, Cascavilla
N, Salutari P, Specchia G, et al. Results of a multicenter, controlled, randomized clinical trial evaluating the combination of piperacillin/tazobactam and tigecycline in high-risk hematologic patients with cancer with febrile neutropenia. J Clin Oncol. 2014;32(14):1463-1471.

53. Patel GW, Patel N, Lat A, Trombley K, Enbawe S, Manor $\mathrm{K}$, Smith R, et al. Outcomes of extended infusion piperacillin/tazobactam for documented Gram-negative infections. Diagn Microbiol Infect Dis. 2009;64(2):236-240.

54. Rolston KV, Bodey GP. Pseudomonas aeruginosa infection in cancer patients. Cancer Invest. 1992;10(1):43-59.

55. Bodey G, Bueltmann B, Duguid W, Gibbs D, Hanak H, Hotchi M, Mall G, et al. Fungal infections in cancer patients: an international autopsy survey. Eur J Clin Microbiol Infect Dis. 1992;11(2):99-109.

56. Nucci M, Anaissie EJ, Queiroz-Telles F, Martins CA, Trabasso P, Solza C, Mangini C, et al. Outcome predictors of 84 patients with hematologic malignancies and Fusarium infection. Cancer. 2003;98(2):315-319.

57. Guerrero A, Torres P, Duran MT, Ruiz-Diez B, Rosales M, Rodriguez-Tudela JL. Airborne outbreak of nosocomial Scedosporium prolificans infection. Lancet. 2001;357(9264):1267-1268.

58. Teoh F, Pavelka N. How chemotherapy increases the risk of systemic candidiasis in cancer patients: current paradigm and future directions. Pathogens. 2016;5(1):6.

59. Wingard JR. Importance of Candida species other than C. albicans as pathogens in oncology patients. Clin Infect Dis. $1995 ; 20(1): 115-125$.

60. Wingard JR, Merz WG, Rinaldi MG, Johnson TR, Karp JE, Saral R. Increase in Candida krusei infection among patients with bone marrow transplantation and neutropenia treated prophylactically with fluconazole. N Engl J Med. 1991;325(18):1274-1277.

61. Wingard JR, Merz WG, Rinaldi MG, Miller CB, Karp JE, Saral R. Association of Torulopsis glabrata infections with fluconazole prophylaxis in neutropenic bone marrow transplant patients. Antimicrob Agents Chemother. 1993;37(9):1847-1849.

62. Pagano L, Caira M, Candoni A, Offidani M, Fianchi L, Martino B, Pastore D, et al. The epidemiology of fungal infections in patients with hematologic malignancies: the SEIFEM-2004 study. Haematologica. 2006;91(8):10681075.

63. Marr KA, Carter RA, Crippa F, Wald A, Corey L. Epidemiology and outcome of mould infections in hematopoietic stem cell transplant recipients. Clin Infect Dis. 2002;34(7):909-917.

64. Wirk B, Wingard JR. Current approaches in antifungal prophylaxis in high risk hematologic malignancy and hematopoietic stem cell transplant patients. Mycopathologia. 2009;168(6):299-311.

65. Mattiuzzi GN, Alvarado G, Giles FJ, Ostrosky-Zeichner L, Cortes J, O'Brien S, Verstovsek S, et al. Open-label, randomized comparison of itraconazole versus caspofungin for prophylaxis in patients with hematologic malignancies. Antimicrob Agents Chemother. 2006;50(1):143147.

66. Madureira A, Bergeron A, Lacroix C, Robin M, Rocha V, 
de Latour RP, Ferry C, et al. Breakthrough invasive aspergillosis in allogeneic haematopoietic stem cell transplant recipients treated with caspofungin. Int $\mathbf{J}$ Antimicrob Agents. 2007;30(6):551-554.

67. Rex JH, Pfaller MA. Has antifungal susceptibility testing come of age? Clin Infect Dis. 2002;35(8):982-989.

68. Tomblyn M, Chiller T, Einsele H, Gress R, Sepkowitz $\mathrm{K}$, Storek J, Wingard JR, et al. Guidelines for preventing infectious complications among hematopoietic cell transplantation recipients: a global perspective. Biol Blood Marrow Transplant. 2009;15(10):1143-1238.

69. Redding SW. Role of herpes simplex virus reactivation in chemotherapy-induced oral mucositis. NCI Monogr. 1990;9:103-105.

70. Saral R, Ambinder RF, Burns WH, Angelopulos CM, Griffin DE, Burke PJ, Lietman PS. Acyclovir prophylaxis against herpes simplex virus infection in patients with leukemia. A randomized, double-blind, placebocontrolled study. Ann Intern Med. 1983;99(6):773-776.

71. Saral R, Burns WH, Laskin OL, Santos GW, Lietman PS. Acyclovir prophylaxis of herpes-simplex-virus infections. N Engl J Med. 1981;305(2):63-67.

72. McCrary ML, Severson J, Tyring SK. Varicella zoster virus. J Am Acad Dermatol. 1999;41(1):1-14; quiz 15-16.

73. Lee HS, Park JY, Shin SH, Kim SB, Lee JS, Lee A, Ye BJ, et al. Herpesviridae viral infections after chemotherapy without antiviral prophylaxis in patients with malignant lymphoma: incidence and risk factors. Am J Clin Oncol. 2012;35(2):146-150.

74. Lai YL, Su YC, Kao CH, Liang JA. Increased risk of varicella-zoster virus infection in patients with breast cancer after adjuvant radiotherapy: A population-based cohort study. PLoS One. 2019;14(1):e0209365.

75. Okuma HS, Kobayashi Y, Makita S, Kitahara H, Fukuhara S, Munakata W, Suzuki T, et al. Disseminated herpes zoster infection initially presenting with abdominal pain in patients with lymphoma undergoing conventional chemotherapy: A report of three cases. Oncol Lett. 2016;12(2):809-814.

76. Dignan FL, Clark A, Aitken C, Gilleece M, Jayakar V, Krishnamurthy P, Pagliuca A, et al. BCSH/BSBMT/UK clinical virology network guideline: diagnosis and management of common respiratory viral infections in patients undergoing treatment for haematological malignancies or stem cell transplantation. Br J Haematol. 2016;173(3):380-393.

77. Zhou F, Yu T, Du R, Fan G, Liu Y, Liu Z, Xiang J, et al. Clinical course and risk factors for mortality of adult inpatients with COVID-19 in Wuhan, China: a retrospective cohort study. Lancet. 2020;395(10229):1054-1062.

78. Hanna TP, Evans GA, Booth CM. Cancer, COVID-19 and the precautionary principle: prioritizing treatment during a global pandemic. Nat Rev Clin Oncol. 2020;17(5):268270.

79. Helsper CW, Campbell C, Emery J, Neal RD, Li L, Rubin $\mathrm{G}$, van Weert $\mathrm{H}$, et al. Cancer has not gone away: A primary care perspective to support a balanced approach for timely cancer diagnosis during COVID-19. Eur J Cancer Care (Engl). 2020;29(5):e13290.

80. Hassan H, Elazar A, Takabe K, Datta R, Takahashi H,
Seitelman E. Scalp leiomyosarcoma: diagnosis and treatment during a global pandemic with COVID-19. World J Oncol. 2021;12(4):132-136.

81. Bow EJ. Fluoroquinolones, antimicrobial resistance and neutropenic cancer patients. Curr Opin Infect Dis. 2011; 24(6):545-553.

82. Pepin J, Saheb N, Coulombe MA, Alary ME, Corriveau MP, Authier S, Leblanc M, et al. Emergence of fluoroquinolones as the predominant risk factor for Clostridium difficile-associated diarrhea: a cohort study during an epidemic in Quebec. Clin Infect Dis. 2005;41(9):1254-1260.

83. Taplitz RA, Kennedy EB, Bow EJ, Crews J, Gleason C, Hawley DK, Langston AA, et al. Antimicrobial prophylaxis for adult patients with cancer-related immunosuppression: ASCO and IDSA clinical practice guideline update. J Clin Oncol. 2018;36(30):3043-3054.

84. Baden LR. Prophylactic antimicrobial agents and the importance of fitness. N Engl J Med. 2005;353(10):10521054.

85. Patterson TF, Thompson GR, 3rd, Denning DW, Fishman JA, Hadley S, Herbrecht R, Kontoyiannis DP, et al. Practice guidelines for the diagnosis and management of aspergillosis: 2016 update by the infectious diseases society of America. Clin Infect Dis. 2016;63(4):e1-e60.

86. Uyeki TM, Bernstein HH, Bradley JS, Englund JA, File TM, Fry AM, Gravenstein S, et al. Clinical practice guidelines by the infectious diseases society of America: 2018 update on diagnosis, treatment, chemoprophylaxis, and institutional outbreak management of seasonal influenzaa. Clin Infect Dis. 2019;68(6):e1-e47.

87. Sommer F, Anderson JM, Bharti R, Raes J, Rosenstiel $\mathrm{P}$. The resilience of the intestinal microbiota influences health and disease. Nat Rev Microbiol. 2017;15(10):630638.

88. Sullivan A, Edlund C, Nord CE. Effect of antimicrobial agents on the ecological balance of human microflora. Lancet Infect Dis. 2001;1(2):101-114.

89. Gao Y, Shang Q, Li W, Guo W, Stojadinovic A, Mannion C, Man YG, et al. Antibiotics for cancer treatment: A double-edged sword. J Cancer. 2020;11(17):5135-5149.

90. Patel RN, Attur MG, Dave MN, Patel IV, Stuchin SA, Abramson SB, Amin AR. A novel mechanism of action of chemically modified tetracyclines: inhibition of COX2-mediated prostaglandin E2 production. J Immunol. 1999;163(6):3459-3467.

91. Attur MG, Patel RN, Patel PD, Abramson SB, Amin AR. Tetracycline up-regulates COX-2 expression and prostaglandin E2 production independent of its effect on nitric oxide. J Immunol. 1999;162(6):3160-3167.

92. Thong YH, Ferrante A. Inhibition of mitogen-induced human lymphocyte proliferative responses by tetracycline analogues. Clin Exp Immunol. 1979;35(3):443-446.

93. Kuczma MP, Ding ZC, Li T, Habtetsion T, Chen T, Hao Z, Bryan L, et al. The impact of antibiotic usage on the efficacy of chemoimmunotherapy is contingent on the source of tumor-reactive T cells. Oncotarget. 2017;8(67):111931111942.

94. Routy B, Le Chatelier E, Derosa L, Duong CPM, Alou MT, Daillere R, Fluckiger A, et al. Gut microbiome in- 
fluences efficacy of PD-1-based immunotherapy against epithelial tumors. Science. 2018;359(6371):91-97.

95. Desoize B. Metals and metal compounds in carcinogenesis. In Vivo. 2003;17(6):529-539.

96. Brewer GJ. Copper control as an antiangiogenic anticancer therapy: lessons from treating Wilson's disease. Exp Biol Med (Maywood). 2001;226(7):665-673.

97. Ding WQ, Liu B, Vaught JL, Yamauchi H, Lind SE. Anticancer activity of the antibiotic clioquinol. Cancer Res. 2005;65(8):3389-3395.

98. Huang P, Feng L, Oldham EA, Keating MJ, Plunkett W.
Superoxide dismutase as a target for the selective killing of cancer cells. Nature. 2000;407(6802):390-395.

99. Ferraz R, Costa-Rodrigues J, Fernandes MH, Santos MM, Marrucho IM, Rebelo LP, Prudencio C, et al. Antitumor activity of ionic liquids based on ampicillin. ChemMedChem. 2015;10(9):1480-1483.

100. Hut EF, Radulescu M, Pilut N, Macasoi I, Berceanu D, Coricovac D, Pinzaru I, et al. Two antibiotics, ampicillin and tetracycline, exert different effects in HT-29 colorectal adenocarcinoma cells in terms of cell viability and migration capacity. Curr Oncol. 2021;28(4):2466-2480. 